\title{
Endemicity of malaria in rural areas: A prospective longitudinal study in India
}

\author{
Mohammad Athar Ansari ${ }^{1}$, Iqbal Mohd Khan ${ }^{2}$ \\ ${ }^{1}$ Associate Professor and Formed Head, ${ }^{2}$ Associate Professor, Department of Community Medicine, J.N. Medical College, Aligarh \\ Muslim University, Aligarh, India.
}

\begin{abstract}
The aim of the study is to assess the magnitude of the problem and certain epidemiological factors associated with malaria and examine the changing pattern of malaria through its parameters of measurement during 2009-2011. The study was carried out at the Rural Health Training Center (RHTC), under the J. N. Medical College, Aligarh Muslim University, Aligarh, (India) for three years from $1^{\text {st }}$ January 2009 to $31^{\text {st }}$ December 2011. Teams of doctors and paramedical staff regularly visited the villages. If any person was found to be suffering from fever, his/her blood was examined for the malaria parasite. Patients were given presumptive treatment and radical treatment if slides were positive. The findings of the study demonstrated that the number of malaria cases increased during the study period, but in the year 2010, a sudden upsurge was noticed. Out of 5594 patients, most of the patients seen were in the age group of $11-20$ years (34.3\%). P. vivax $(96.2 \%)$ was the most common malaria infection in these areas. An increasing trend of malaria was seen from July to October. Most of the parameters of malaria measurement increased many folds in 2010 and showed a declining trend in 2011. The overall findings of the study indicated the high endemicity of malaria in the study area and demonstrated a changing pattern of malaria in the registered villages as most of the parameters of malaria measurement increased. An integrated approach is needed which includes mass survey or active surveillance, and appropriate drug therapy to tackle this public health problem.
\end{abstract}

Keywords: Plasmodium vivax, Plasmodium falciparum, Annual Blood Examination Rate, Annual Parasite Index, Annual Falciparum Index.

\section{Introduction}

Malaria is one of the major public health problems in the developing world and accounts for 300 to 500 million cases and more than 1 million deaths annually. ${ }^{1}$ In South East Asia Region (SEAR), an estimated 23 million new cases occur annually. The disease is thought to kill 34,000 people each year in this region. ${ }^{2}$ India is one of the highly endemic countries and reports about 1.8 millions cases per year, of which $40-50 \%$ are due to Plasmodium falciaprum. ${ }^{3}$ A recent study estimated that the number of malaria deaths in India could well be as much as 6-fold higher than the current World Health Organization (WHO) estimates. ${ }^{4}$

After the introduction of National Malaria Control Programme in 1953 and Malaria Eradication Programme in 1958, the success was short lived and setback occurred. $^{5}$ The cases of malaria re-emerged, including cases of P. falciparum. A modified plan of operation was launched in 1977 to control the alarming situation. ${ }^{6}$ Again, the number of cases dropped to 2.1 million in 1984. However, after these successes, no significant improvement has been achieved yet. In the last few years, various parts of the country have witnessed sudden upsurge of falciparum malaria epidemics, especially in the states of Rajasthan, Haryana, Manipur and Nagaland. ${ }^{7}$

Increasing multi-drug resistant $\mathrm{P}$. falciparum cases, the development of chloroquin resistant P. vivax and

\section{Practice Points}

- Malaria is one of the major public health problems in India

- The findings of the present investigation showed that in 2010, a sudden upsurge of malaria cases was noticed in the study area.

- Plasmodium vivax was the most common infection.

- The overall finding indicated high endemicity of malaria as most of the parameters of malaria measurement increased.

- An integrated approach is needed which includes mass survey or active surveillance, and appropriate drug therapy to tackle this public health problem.

conventional insecticide resistance in mosquitoes has made the present malaria situation more gloomy and causing concern. ${ }^{8}$ The present National Drug Policy on Malaria (2010) has been drafted keeping in view the availability of more effective antimalarial drugs and drug resistance status in the country. ${ }^{9}$ The aim of the study is to assess the magnitude of the problem and certain epidemiological factors associated with

Correspondence: Dr. M. Athar Ansari, Associate Professor, Department of Community Medicine, J.N. Medical College, Aligarh Muslim University, Aligarh, India-2002002. Email: atharansari777@rediffmail.com. 
malaria and examine the changing pattern of malaria through its parameters of measurement during 20092011.

\section{Materials and methods}

The present study was carried out at a Rural Health Training Center (RHTC), under the Department of Community Medicine, J. N. Medical College, Aligarh Muslim University, Aligarh, (India) for three years from $1^{\text {st }}$ January 2009 to $31^{\text {st }}$ December 2011 . With their vast canal network in a semi-arid setting, the rural areas under RHTC provide a fertile ground for the propagation of malaria. Hence, these areas can prove to be ideally situated for the study. With a geographically demarcated target population of seven villages, its trained health workforce helped in blood collection and examination of slides of suspected patients of malaria. The registered villages under RHTC and their population are given in Table 1 .

Keeping in mind the current growth rate $(1.3 \%)$ in the study area, total population of the registered area was 14,213 (an increase of 182) and 14,398 (an increase of 185 ) in 2010 and 2011 respectively. Teams of health professionals, medical interns and paramedical staff, including medico-social workers regularly visited the villages for family health studies, routine immunization against six killer diseases, antenatal and family planning services. If any person in these villages was found to be suffering from fever with or without chills and rigors, s/ he was asked to visit the RHTC on the same day or next day for blood examination and to take treatment for fever. Sometime teams brought patients to RHTC after the end of visit on the same day to make sure the blood examination of the patients was done. Because of awareness, most of the time patients themselves visited the center to get their blood tested for malaria and to collect medicines. When patients came to RHTC, their personal details and history of present illness was taken. They were thoroughly examined, particularly for pallor and spleen enlargement. Temperature was noted down. Their blood samples were taken on a slide by the prick method and thick and thin films were made. Staining of the slides was done by Giemsa stain. Slides were examined microscopically under high power.

After taking blood samples, patients were given presumptive treatment for malaria and paracetamol for fever. They were also asked to carry out cold sponging in high grade fever. Patients were told to come to RHTC on the next day to collect the blood report and to take radical treatment if slides were positive for malaria parasites. They were also motivated to ask other family members and neighbors to get tested for malaria parasites if any of them had a high grade fever. Various parameters of malaria measurement were calculated to know the magnitude of the problem and operational efficiency.

Data was collected, tabulated and analyzed using SPSS 12. Ethical clearance was taken from Institutional Ethical Committee. Informed consent was also taken from the patients and their guardians in case of minors.

\section{Results}

Figure 1 shows the cases of malaria in last seven years (2005-2011) in the registered villages under Rural Health Training Centre (RHTC). It is to be mentioned that records were checked for malaria cases reported at RHTC during seven years, however, study was conducted for three years from 2009-2011). The Number of malaria cases increased in a gradual manner until 2009, but a sudden upsurge was noticed in 2010. This outburst of malaria cases could be attributed to climate change. In 2010, the western part of Uttar Pradesh including Aligarh experienced heavy rainfall which might help in the breeding of mosquitoes. In the year 2011, a declining trend was observed in these areas.

Table 2 presents a distribution of study population according to age. Out of 5594 patients, most of the patients were seen in the younger age groups, the maximum being in the age group of $11-20$ years $(37.9 \%)$ followed by $1-10$ years $(27.0 \%)$ and $21-30$ years $(12.6 \%)$. Table 3 depicts the distribution of smear positive malaria cases. It was observed that out of 5,594 blood slides examined over three years (2009-2011), the total number of malaria positive smears was 1,761 (31.4\%); P. vivax accounted for 1,694 (96.2\%) cases and $\mathrm{P}$. falciparum was detected in only $67(3.8 \%)$ patients. The total number of patients suffering from fever who attended the centre to get their blood tested for the malaria parasite was 1761 , while the largest number of malaria patients were from Jawan, 950 (53.9\%) (Table 4 ). The second highest numbers of malaria patients were from Sumera, 278 patients $(15.8 \%)$.

Table 1: Population of registered villages under RHTC

\begin{tabular}{|c|l|c|c|c|c|c|c|}
\hline No & \multicolumn{1}{|c|}{ Villages } & $\begin{array}{c}\text { No of } \\
\text { Families }\end{array}$ & Males & Females & $\begin{array}{c}\text { Population } \\
\mathbf{2 0 0 9}\end{array}$ & $\begin{array}{c}\text { Population } \\
\mathbf{2 0 1 0}\end{array}$ & $\begin{array}{c}\text { Population } \\
\mathbf{2 0 1 1}\end{array}$ \\
\hline 1. & Jawan & 924 & 2973 & 2615 & 5588 & 5661 & 5734 \\
\hline 2. & Jawan Sikandpur & 136 & 400 & 363 & 763 & 773 & 783 \\
\hline 3. & Chhota Jawan & 263 & 802 & 698 & 1500 & 1520 & 1540 \\
\hline 4. & Garhiya Bhojpur & 184 & 483 & 402 & 885 & 896 & 908 \\
\hline 5. & Tejpur & 267 & 822 & 685 & 1507 & 1526 & 1546 \\
\hline 6. & Sumera Jhal & 47 & 117 & 127 & 244 & 247 & 250 \\
\hline 7. & Sumera & 593 & 1928 & 1616 & 3544 & 3590 & 3637 \\
\hline & Total & $\mathbf{2 4 1 4}$ & $\mathbf{7 5 2 5}$ & $\mathbf{6 5 0 6}$ & $\mathbf{1 4 0 3 1}$ & $\mathbf{1 4 2 1 3}$ & $\mathbf{1 4 3 9 8}$ \\
\hline
\end{tabular}

South East Asia Journal of Public Health 2012;2(2):28-33. 


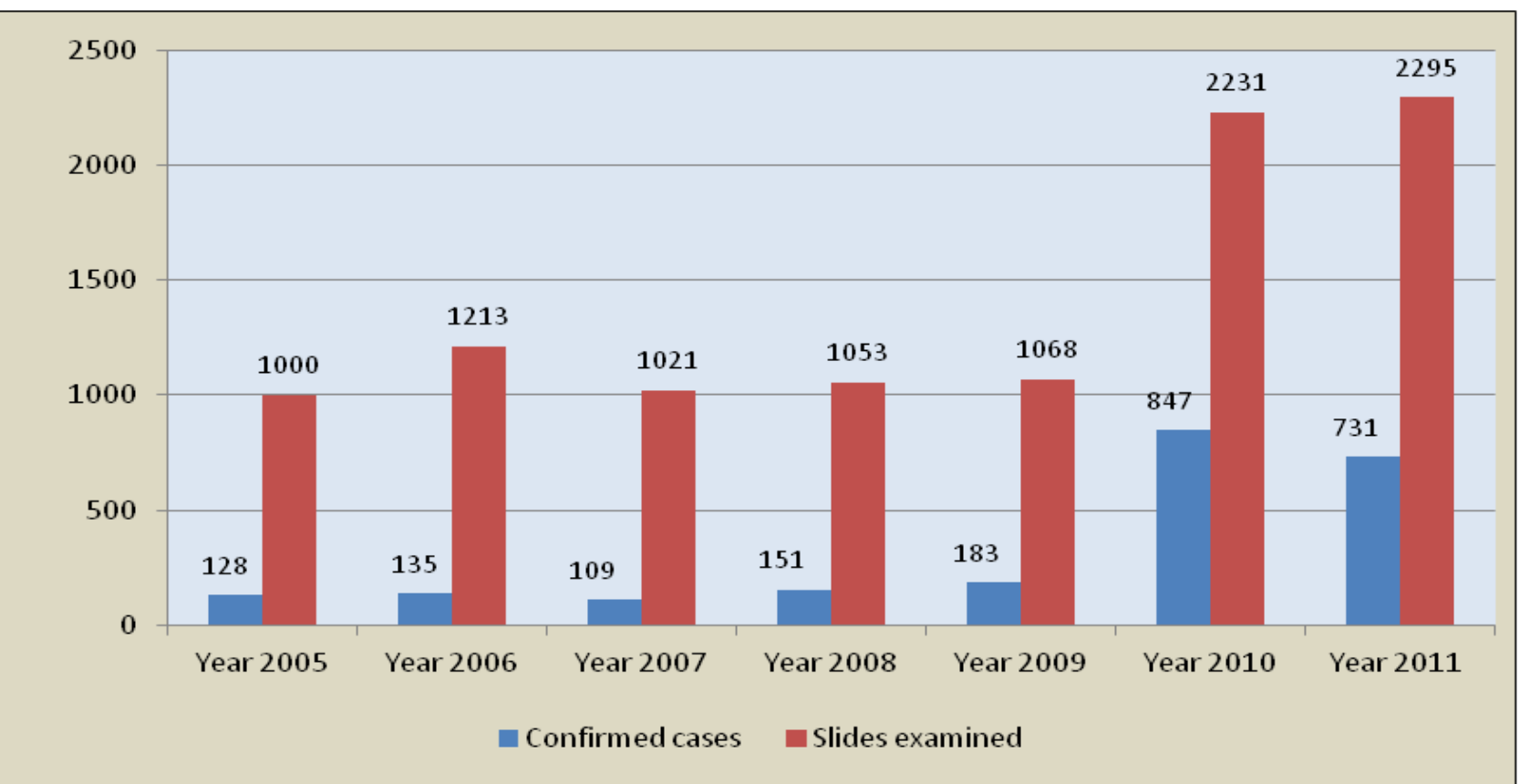

Figure 1: Trends of Malaria at RHTC (2005-2011)

\section{Parameters of Malaria Measurement (2009)}

Various parameters of malaria measurement were calculated for the three years (2009-11) by using the following formulae: ${ }^{10}$

i. Annual blood examination rate (ABER):

$$
=\frac{\text { No. of slide examined }}{\text { Population under surveillance }} \times 100
$$

ii. Annual parasite index (API):

$$
=\frac{\text { Confirmed cases during one year }}{\text { Population under surveillan ce }} \times 1000
$$

iii. Annual Falciparum index (AFI):

$$
=\frac{\text { Confirmed cases of P. falciparum }}{\text { Population under surveillan ce }} \times 1000
$$

iv. Slide positivity rate (SPR):

$$
=\frac{\text { No. of positive slides }}{\text { Total no. of slides examined }} \times 100
$$

Table 2: Pattern of co-existence of infections v. Slide Falciparum rate (SFR):

$$
=\frac{\text { No. of positive P.falciparum slides }}{\text { Total no. of slides examined }} \times 100
$$

vi. P. Falciparum percentage $(\mathrm{PF} \%)$ :

$$
=\frac{\text { No. of confirmed P.falciparum slides }}{\text { Total no. of positivity slides }} \times 100
$$

The results of the various parameters of malaria measurement are shown in Table 5. The findings show that most of the parameters of malaria measurement in 2010 increased many folds. The ABER increased from 7.6\% in 2009 to $15.7 \%$ in 2010 . The API and AFI rose four and three times respectively. The SPR also increased in 2010 from 17.1 to $38.0 \%$. Most of the parameters were showing a declining trend in 2011.

Figure 2 illustrates the monthly incidence of malaria cases. It was observed that during the rainy season in the year 2009, 2010 and 2011, more cases were reported. However, there was sudden upsurge of malaria cases in 2010 including P. falciparum cases and peak was noticed in September.

\begin{tabular}{|c|c|c|c|c|c|c|c|c|c|}
\hline \multirow{2}{*}{ No. } & \multirow{2}{*}{$\begin{array}{c}\text { Age Group } \\
\text { (Years) }\end{array}$} & \multicolumn{2}{|c|}{$\mathbf{2 0 0 9}$} & \multicolumn{2}{c|}{$\mathbf{2 0 1 0}$} & \multicolumn{2}{c|}{ T011 } & \multicolumn{2}{c|}{ Total } \\
\cline { 2 - 9 } & No. & $\mathbf{\%}$ & No. & \% & No. & \% & No. & \% \\
\hline 1. & $0-1$ & 11 & 1.0 & 27 & 1.2 & 21 & 0.9 & 59 & 1.1 \\
\hline 2. & $1-10$ & 319 & 29.9 & 571 & 25.6 & 620 & 27.0 & 1510 & 27.0 \\
\hline 3. & $11-20$ & 366 & 34.3 & 874 & 39.2 & 879 & 38.3 & 2119 & 37.9 \\
\hline 4. & $21-30$ & 141 & 13.2 & 265 & 11.9 & 300 & 13.1 & 706 & 12.6 \\
\hline 5. & $31-40$ & 100 & 9.4 & 214 & 9.6 & 204 & 8.9 & 518 & 9.3 \\
\hline 6. & $41-50$ & 52 & 4.9 & 118 & 5.3 & 126 & 5.5 & 296 & 5.3 \\
\hline 7. & $51-60$ & 44 & 4.1 & 100 & 4.5 & 115 & 5.0 & 259 & 4.6 \\
\hline 8. & More than 60 & 35 & 3.3 & 62 & 2.8 & 30 & 1.3 & 127 & 2.3 \\
\hline & Total & $\mathbf{1 0 6 8}$ & $\mathbf{1 0 0}$ & $\mathbf{2 2 3 1}$ & $\mathbf{1 0 0}$ & $\mathbf{2 2 9 5}$ & $\mathbf{1 0 0}$ & $\mathbf{5 5 9 4}$ & $\mathbf{1 0 0}$ \\
\hline
\end{tabular}

South East Asia Journal of Public Health 2012;2(2):28-33. 
Table 3: Types of malaria parasite in smear positive cases

\begin{tabular}{|c|l|c|c|c|c|c|c|c|c|}
\hline No & \multirow{2}{*}{$\begin{array}{c}\text { Malaria } \\
\text { parasite }\end{array}$} & \multicolumn{2}{|c|}{$\begin{array}{c}\mathbf{2 0 0 9} \\
(\mathrm{n}=1068)\end{array}$} & \multicolumn{2}{c|}{$\begin{array}{c}\mathbf{2 0 1 0} \\
(\mathrm{n}=2231)\end{array}$} & \multicolumn{2}{c|}{$\begin{array}{c}\mathbf{2 0 1 1} \\
(\mathrm{n}=2295)\end{array}$} & \multicolumn{2}{c|}{$\begin{array}{c}\text { Total } \\
(\mathrm{n}=5594)\end{array}$} \\
\cline { 3 - 10 } & & Cases & $\mathbf{\%}$ & Cases & $\mathbf{\%}$ & Cases & \% & Cases & $\%$ \\
\hline 1. & P. vivax & 181 & 98.9 & 800 & 94.5 & 713 & 97.5 & 1694 & 96.2 \\
\hline 2. & P. falciparum & 02 & 1.1 & 47 & 5.5 & 18 & 27.0 & 67 & 3.8 \\
\hline & Total & $\mathbf{1 8 3}$ & $\mathbf{1 0 0}$ & $\mathbf{8 4 7}$ & $\mathbf{1 0 0}$ & $\mathbf{7 3 1}$ & $\mathbf{1 0 0}$ & $\mathbf{1 7 6 1}$ & $\mathbf{1 0 0}$ \\
\hline
\end{tabular}

Table 4: Distribution of malaria cases in registered areas

\begin{tabular}{|c|l|c|}
\hline No & \multicolumn{1}{|c|}{ Villages } & Cases (\%) \\
\hline 1. & Jawan & $950(53.9 \%)$ \\
\hline 2. & Jawan Sikandarpur & $166(9.4 \%)$ \\
\hline 3. & Gadhia Bhojpur & $112(6.4 \%)$ \\
\hline 4. & Chhota Jawan & $146(8.3 \%)$ \\
\hline 5. & Sumera & $278(15.8 \%)$ \\
\hline 6. & Sumera Jhal & $25(1.4 \%)$ \\
\hline 7. & Tejpur & $84(4.8 \%)$ \\
\hline \multicolumn{2}{|c|}{ Total } \\
\hline
\end{tabular}

Table 5: Parameters of malaria measurement in registered areas

\begin{tabular}{|c|l|c|c|c|}
\hline No & $\begin{array}{c}\text { Parameters of } \\
\text { malaria } \\
\text { measurement }\end{array}$ & $\begin{array}{c}\text { Year } \\
\mathbf{2 0 0 9}\end{array}$ & $\begin{array}{c}\text { Year } \\
\mathbf{2 0 1 0}\end{array}$ & $\begin{array}{c}\text { Year } \\
\mathbf{2 0 1 1}\end{array}$ \\
\hline 1. & ABER & $7.6 \%$ & $15.7 \%$ & $15.9 \%$ \\
\hline 2. & API & 13.0 & 59.6 & 50.8 \\
\hline 3. & AFI & 0.1 & 3.3 & 1.2 \\
\hline 4. & SPR & $17.1 \%$ & $38.0 \%$ & $31.8 \%$ \\
\hline 5. & SFR & $0.2 \%$ & $2.1 \%$ & $0.8 \%$ \\
\hline 6. & PF\% & $1.1 \%$ & $5.5 \%$ & $2.5 \%$ \\
\hline
\end{tabular}

Keys: ABER: Annual Blood Examination Rate; API: Annual Parasite Index; AFI: Annual Falciparum Index; SPR: Slide Positivity Rate; SFR: Slide Falciparum Rate; $\mathrm{PF} \%$ : P. falciparum Percentage.

\section{Discussion}

From the findings of the study, it has been observed that $\mathrm{P}$. vivax is the most common malaria infection in these rural areas. Similar observations were also made in neighboring Haryana. ${ }^{11}$ Similarly in Sri Lanka, the majority of the malaria cases were caused by $P$. vivax. $^{12}$ However in the Purulia district of West Bengal, a tribal dominated area, P. falciparum infection was the most common $(20 \%)$ followed by P. vivax $(6.4 \%) .{ }^{13}$ In Ethiopia, P. falciparum and P. vivax were also the dominant human malaria parasites but contrary to our findings $\mathrm{P}$. falciparum was more common $(60 \%)$ than P. vivax $(40 \%) .{ }^{14}$

Suspected malaria infection in a higher number of the younger population may be attributed to the fact that they are more vulnerable to the infection. Adults and older age people are more protected either due to presence of immunity or by protective measures. ${ }^{15,16}$ Infants are comparatively more protected if born to immune mothers during first few months of life by presence of $\mathrm{IgG}$ antibodies. It has also been observed that a high concentration of hemoglobin during early months of life in infants suppresses the development of P. falciparum infection. ${ }^{10}$

The majority of patients suffering from fever attended the centre to get their blood tested for malaria parasite were from Jawan village which is situated very close to the centre $(0.5 \mathrm{Km})$. Its closeness to the centre might be a factor for the maximum utilization of health care services. The reason for maximum endemicity in this village could be the Upper Ganga Canal just behind this village, water stagnation in the village and the poorly maintained reservoirs of the nearby thermal power station.

It was also found that the reported cases were less frequent in the month of October as the temperature dropped at that time. Similarly, in very hot and humid conditions, cases could not be detected. In India, rainfall in the month of July to September provides an opportunity for breeding of mosquitoes. However, heavy rainfall or flooding also has an adverse effect on breeding of mosquitoes. The results obtained in the study are corroborated by the studies carried out in the Sonebhadra district of the Uttar Pradesh province of India ${ }^{17}$ and in southern Ethiopia. ${ }^{14}$

Annual Blood Examination Rate is an index of operation efficiency. API depends upon the annual blood collection and examination rate. A sufficient number of blood slides must be obtained and examined for the malaria parasite to work out the API accurately. ${ }^{10}$ To improve the coverage, a nearby Government run Community Health Centre (CHC) and RHTC should work together and share the data. If data from $\mathrm{CHC}$ is taken, ABER will be much more than obtained in the present study. API in the present study was higher than the other study. ${ }^{18}$ Similarly, low AFI is also reported by researchers from nearby areas. ${ }^{17}$

Malaria mortality and morbidity may be reduced significantly by improving diagnostic tests, and management of the cases to prevent further unwanted complications. A sustainable community based system from diagnoses and treatment through community health workers, school teachers, influential people, religious leaders etc. would be more effective. There is an urgent need to increase the awareness regarding climate change and the possibility of increased incidence of vector borne diseases and their prevention. Community participation through information, education and communication activities is the one of the keys of the success. 
Figure 2: Monthly trend of malaria cases from 20092011

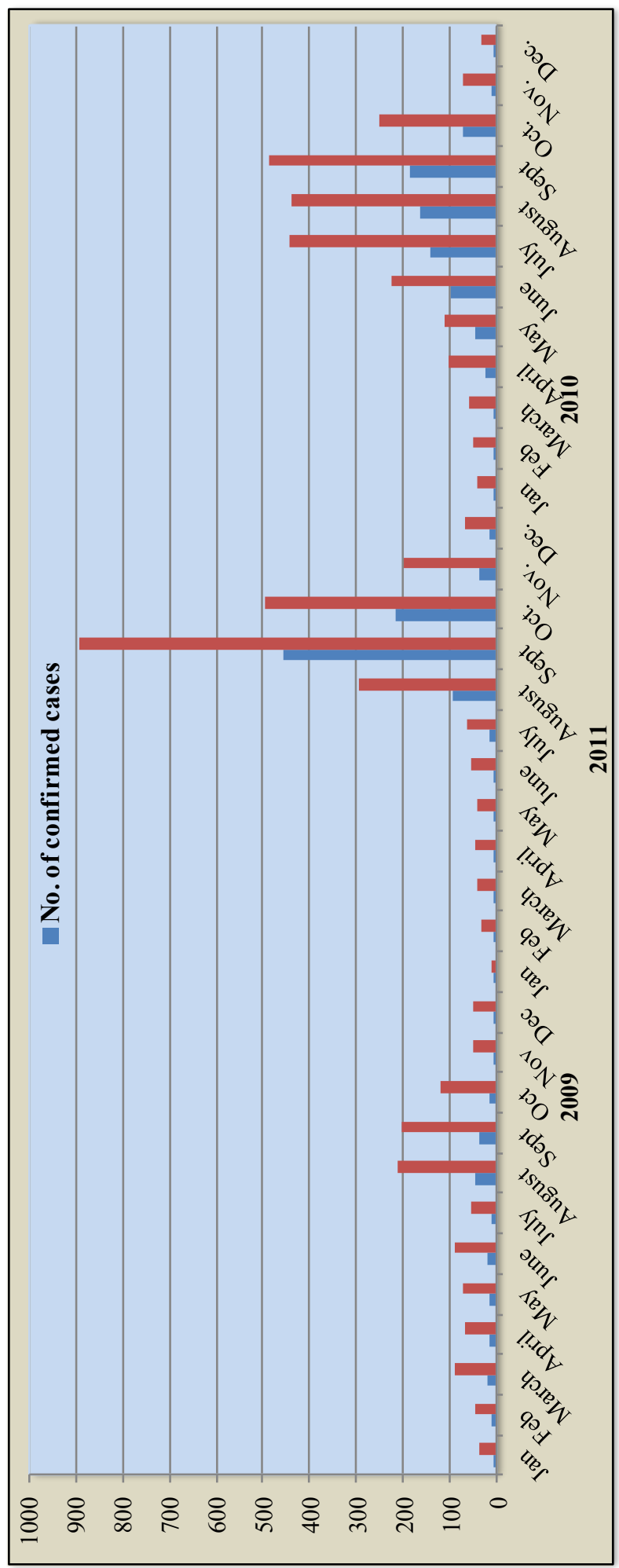

\section{Limitations}

It should be noted that there may be under reporting of the cases. However, as far as P. falciparum infection is concerned, very low incidence has been reported as compared to P. vivax. Major drawback in the data collection is that this study was conducted at the RHTC. The nearby Government run Community Health Center can be asked to share its data so that real picture will emerge.

\section{Conclusion}

The findings of this study confirmed that malaria endemicity is very high in the study area and the major outbreak of malaria was caused by P. vivax rather than P. falciparum. Most of the patients seen were in the age group of 11-20 years old. An increasing trend of malaria infection was noticed in the study area and this could be attributed to change of climate conditions like heavy rainfall. There is a seasonal variation in the incidence, the peak being in the month of August and September. An integrated approach is needed which includes mass survey or active surveillance, appropriate drug therapy, spraying of insecticide and environmental sanitation before July. Special attention should be given to the children and females.

\section{References}

1. WHO. World Malaria Report 2008. Geneva: World Health Organization, 2008.

2. Directorate General of Health Services. National Vector Borne Disease Control Programme. Malaria. http://www.nvbdcp.gov.in/malarianew.html (accessed Nov 2012).

3. National Drug Policy on Malaria (2010). Directorate of National Vector borne Disease Control Programme. New Delhi: Ministry of Health and Family Welfare, Govt. of India, 2010.

4. Dhingra N, Jha P, Sharma VP, Cohen AA, Jotkar RM, Rodriguez PS, et al. Adult and child malaria mortality in India: a nationally representative mortality survey. Lancet 2010;376:1768-74.

5. Shah NK, Dhillon GPS, Dash AP, Arora U, Meshnick SR, Valecha N. Antimalarial drug resistance of Plasmodium falciparum in India: changes over time and space. Lancet Infect Dis 2011;11:57-64.

6. aaraygo.com. National Malaria Control Programme. http://www.aarogya.com/healthresources/health-programs/2634-national-malaria -control-programme-html (accessed Nov 2012).

7. Lal S, Sonal GS, Phukan PK. Status of Malaria in India. J Indian Acad Clin Med 2000;5:19-23.

8. Farooq U, Mahajan RC. Drug resistance in malaria. J Vector Borne Dis 2004;41:45-53.

9. Tikar SN, Mendki MJ, Sharma AK, Sukumaran D, Veer V, Prakash S, Parashar BD. Resistance status of the malaria vector mosquitoes, Anopheles stephensi and Anopheles subpictus towards adulticides and larvicides in arid and semi-arid areas of India. J Insect Sci 2011;11:1-8.

10. Park K. Park's Textbook of Preventive and Social Medicine. $22^{\text {th }}$ Edition. Jabalpur: Banarsidas Bhanot, 2013. 
11. Srivastava A, Nagpal BN, Saxena R, Wadhwa TC, Mohan S, Siroha GP, Prasad J, Subbarao SK. Malaria epidemicity of Mewat region, District Gurgaon, Haryana, India: a GIS-based study. Curr Sci 2004;86:1297-1303.

12. Konradsen F, Steele P, Perera D, Hock W V, Amarasinghe F P. Cost of Malaria Control in Sri Lanka. Bull World Health Organ 1997;77:301-9.

13. Mukhopadhyay AK, Hati AK, Dey P. Malariogenic situation in areas of Aiodhya Hills of District Purulia West Bengal and its present status. Indian J Public Health 2001;45:31-32.

14. Deressa W, Ali A, Engusellarsae F. Self treatment of malaria in rural communities, Butajira, Southern Ethiopia. Bull World Health Organ 2003;81:261-8.

15. Denise L. Doolan, Carlota Dobaño, J. Kevin Baird. Acquired Immunity to Malaria. Clinical Microbiol Rev 2009;22:13-36.
16. Arguin PM, Mali S. Infectious Diseases Related to Travel. Malaria. http://wwwnc.cdc.gov/travel/ yellowbook/2012/chapter-3-infectious-diseasesrelated-to-travel/malaria (accessed Nov 2012).

17. Shankar H. Trend of malaria transmission in Shakti Nagar, District Sonebhadra. Public Health in New Millennium- Joint National Conference of Indian Public Health Association, India Association of Epidemiologists and Indian Society for Malaria and Other Communicable Diseases, Agra, 10-12 March, 2000.

18. Sashikant KA, Samantaray JC, Kapoor SK. Validation of clinical Algorithm for passive surveillance of malaria in low endemic area in Haryana. Public Health in New Millennium- Joint National Conference of Indian Public Health Association, India Association of Epidemiologists and Indian Society for Malaria and Other Communicable Diseases, Agra, 10-12 March, 2000. 